\title{
CARACTERIZACIÓN ECOHIDROLÓGICA DE HUMEDALES ALTO ANDINOS USANDO IMÁGENES DE SATÉLITE MULTITEMPORALES EN LA CABECERA DE CUENCA DEL RÍO SANTA, ANCASH, PERÚ
}

\section{ECOHYDROLOGICAL CHARACTERIZATION OF HIGH ANDEAN WETLANDS BASED ON MULTI-TEMPORAL REMOTE SENSING IMAGES IN THE CASE OF UPPER SANTA RIVER, ANCASH, PERU}

\author{
Erick Garcia ${ }^{1}$ y Marco Otto ${ }^{2}$
}

\begin{abstract}
Resumen
Los Humedales Alto Andinos (HAA-también conocidos localmente como bofedales) pertenecen a un tipo de ecosistema que se caracteriza por tener una vegetación perenne dentro del paisaje semiárido de los altos Andes. El agua subterránea originada de las lluvias y el deshielo de los glaciares y la fusión de nieve es la principal fuente de agua de estos HAA. Los HAA también juegan un rol importante en la provisión y regulación de agua de la cuenca. En este estudio se realizó un análisis multitemporal basado en imágenes de satélite para determinar patrones espaciotemporales vinculados a las características ecohidrológicas de los HAA. La delimitación de los HAA dentro de la zona de estudio se basó en el Índice de la Diferencia Normalizada de la Vegetación (NDVI). Como resultado, se determinó que la cubierta de HAA representa el 25\% de la superficie. El análisis espaciotemporal de la cubierta de nieve derivada de las imágenes del Espectroradiómetro de Imágenes de Resolución Moderada (MODIS) indicó que el 71\% ( $\left.\mathrm{r}^{2}=0.71\right)$ de la varianza en la extensión espacial de los HAA perennes puede ser explicada por la varianza de la cubierta de nieve entre los años 2000 y 2009. El análisis basado en la información anual de las imágenes de la Misión de Medición de Lluvias Tropicales (TRMM) indicó que el 68\% $\left(\mathrm{r}^{2}=0.68\right)$ de la varianza en la extensión espacial de los HAA temporales puede ser explicada por la varianza de la lluvia caída en la época húmeda. Nuestros resultados indican que la extensión espacial de los HAA es altamente dependiente de la precipitación. Los diferentes tipos y subtipos de HAA dependen en gran medida de la cantidad, la dinámica temporal y los tipos de precipitación. Nuestros resultados confirman los obtenidos en otra parte de la región semiárida alto andina y probablemente se pueden considerar como generales. El método aplicado para delimitar los HAA indica que los inventarios actuales probablemente subestiman la extensión actual de esta cubierta. La información y las hipótesis hechas en este estudio son de alta importancia para la conservación de estos frágiles ecosistemas tanto a nivel local y regional, en un contexto de cambio climático y protección de fuentes de agua en cabecera de cuencas andinas.
\end{abstract}

Palabras clave: Teledetección, bofedales, NDVI, NDII, cambio climático.

\begin{abstract}
High Andean Wetlands (HAW - also locally known as bofedales) belong to a type of ecosystem that is characterized by perennial vegetation within semi-arid environments of the high Andes. Ground waters originated from rainfall, glaciers and snowmelt are to be thought as the primary water sources for HAW. HAW may also play an important role in basin water provision and regulation. In this study we conducted a multi-temporal analysis based on remote sensing data to determine spatiotemporal patterns bound to ecohydrological characteristics of HAW. Delineation of HAW within the study region was based on Normalized Difference Vegetation Index (NDVI). As a result, HAW cover represents $25 \%$ of the headwaters region. Spatiotemporal analyses of snow cover derived from the Moderate Resolution Imaging Spectroradiometer (MODIS) indicated that $71 \%\left(\mathrm{r}^{2}=0.71\right)$ of variance in spatial extent of perennial HAW can be explained by the spatial variance in snow cover from 2000 to 2009. Analyses based on annual data of Tropical Rainfall Measuring Mission (TRMM) indicated that $68 \%\left(r^{2}=0.68\right)$ of the variance in spatial extent of temporal HAW is explained by variance in wet-season rainfall. Our results indicate that HAW spatial extent is highly dependent on precipitation. Different HAW types and sub-types strongly depend on the amount, temporal dynamics and type of precipitation. Our
\end{abstract}


assumptions confirm the findings made elsewhere and are likely to be stated as general for other regions in the semi-arid part of the high Andes. The applied method of mapping HAW indicates that current wetland inventories probably underestimate the actual extend of HAW cover. This information and the assumptions made are of paramount importance for local and regional resource management e.g. in the context of climate change and water resource protection in Andean headwater basins.

Key words: Remote sensing, peatlands, NDVI, NDII, Climate change.

\section{Introducción.}

Los Humedales Alto Andinos (HAA), también conocidos como bofedales, oconales o turberas, son un tipo particular de humedales que se ubican en las biorregiones de páramo, jalca y puna; asociados a quebradas, ríos, bordes de lagunas, manantiales y aguas de deshielo (Convención de Ramsar \& Grupo de Contacto EHAA, 2008).

Los HAA son ecosistemas que se encuentran vinculados de manera perenne o temporal a la presencia de agua, ya sea de la proveniente de lluvias, quebradas, aguas subterráneas, deshielo de glaciares o fusión de nieve (Tapia \& Flores, 1984; Alzerreca et al., 2001; Squeo et al., 2006).

Los HAA, son considerados ambientes frágiles por la Convención de Ramsar (2010). Su alta fragilidad está asociada a sequías en la puna y a causas antrópicas como: agricultura, pastoreo intensivo que destruyen el páramo y la puna (Convención de Ramsar \& Grupo de Contacto EHAA, 2008).

Los HAA juegan un rol vital en la formación de las cuencas andinas al proveer servicios ecosistémicos vitales como: agua, regulación hídrica, hábitat de flora y fauna generalmente endémica y refugio de aves migratorias (Convención de Ramsar \& Grupo de Contacto EHAA, 2008). Además, los HAA representan un valor económico muy grande para la población andina, porque desde épocas prehispánicas les proporcionaron pastos por ser zona ganadera (Treacy, 1994). No obstante, estas actividades: sobrepastoreo, quema y el mal manejo de estos HAA han ocasionado su pérdida (Tapia \& Flores, 1984).

En el Perú los HAA generalmente se encuentran por encima de los $4000 \mathrm{msnm}$. Aunque esta altitud es variable, dependiendo del sector de los Andes en el que se ubiquen, siendo su altitud mayor en los Andes del Centro y del Sur y menor en los Andes del Norte. Aunque actualmente en el Perú no existe un inventario nacional de HAA, se han hecho esfuerzos por generar información cartográfica en algunas entidades del Estado con competencias en el tema como el ex Instituto Nacional de Recursos Naturales (INRENA), La Autoridad Nacional del Agua (ANA) y el Ministerio del Ambiente (MINAM). Una muestra de esto, es el mapa de cobertura vegetal del Perú elaborado por el MINAM (2012), el cual incluyó como un tipo de cobertura vegetal a los bofedales. Cabe indicar que existen cifras sobre la extensión de HAA para el país y la región (Convención de Ramsar
\& Grupo de Contacto EHAA, 2008), pero son basados solo en la extensión de los sitios Ramsar.

Por otra parte, se conoce muy poco sobre la relación de los HAA con la hidrología y climatología a nivel local y regional (Otto et al., 2011), más aun en un contexto de cambio climático, en el que muchos investigadores han proyectado cambios en la precipitación y la temperatura en estas biorregiones. Aunque los modelos climáticos en la región Andina aún tienen mucha incertidumbre, se pronostica un aumento de la temperatura (Díaz et al., 2003) y cambios en el régimen de la precipitación (Buytaert et al., 2011). En el caso de la región Andina Peruana se proyecta un aumento de la precipitación en la región norte y una disminución en la región sur (Haylock et al., 2006, Buytaert et al., 2011).

De acuerdo al Grupo Intergubernamental de Expertos sobre el Cambio Climático (IPCC) de las Naciones Unidas, los humedales están entre los ecosistemas más vulnerables al cambio climático. Se menciona, por ejemplo, que los humedales continentales resultarán afectados por los cambios en la precipitación y el incremento de la frecuencia e intensidad de las sequías, tormentas e inundaciones.

En ese contexto, existe la necesidad de generar información sobre los humedales de la región andina. En ese sentido la teledetección, a través del análisis de las imágenes capturadas por los satélites de observación terrestre, han demostrado ser de una herramienta única para generar información espacial sobre HAA (Quiroz \& Saatchi, 1999; Postigo et al., 2008; Otto et al., 2011; García \& Lleellish, 2012). La Convención Ramsar, por ejemplo, recomienda el uso de esta tecnología para el desarrollo de inventarios nacionales (Convención de Ramsar, 2010). Asimismo, aplicando sobre estas imágenes satelitales distintos algoritmos es posible generar información sobre aspectos hidrológicos y ecológicos de los HAA (Moreau et al., 2003, Washington-Allen et al., 2008; Gibbons, 2012; Zorogastua et al., 2012).

Otto et al. (2011), usaron imágenes de los satélites Landsat y MODIS, y a través de índices espectrales encontraron la distribución espacial y temporal de los HAA localizados en la región sur del Perú, dentro de la ecorregión Puna seca. Después, diferenciaron hidrológicamente los HAA en función de la recurrencia de su inundación. Finalmente analizaron la conexión entre los tipos de HAA identificados y la lluvia y la acumulación de nieve en dicha región 


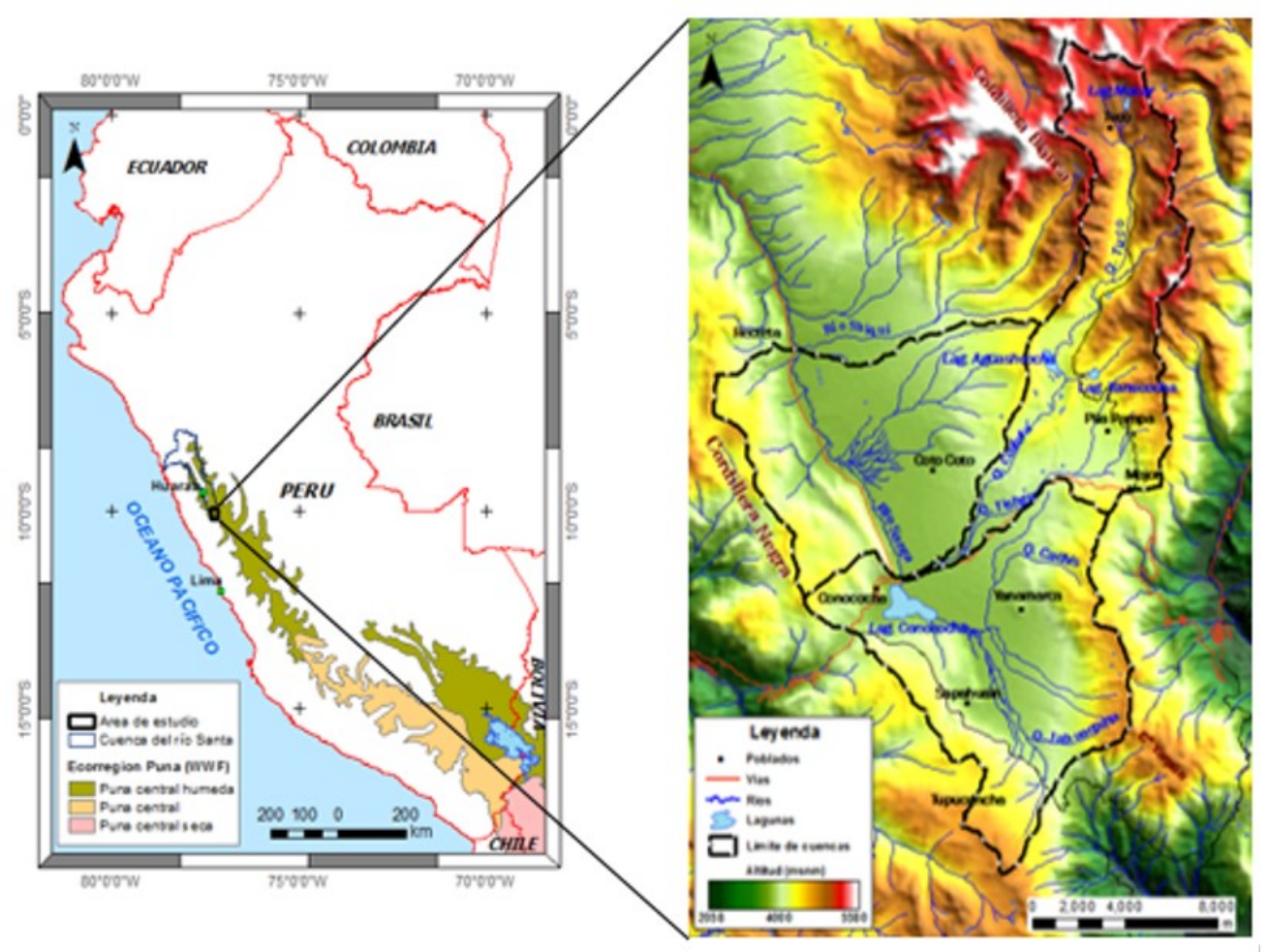

Figura 1. Área de estudio. A la derecha se muestra el límite de la cuenca del rio santa y de la región Puna según WWF. A la izquierda se muestra el límite de la cuenca de estudio.

incluyendo el uso de las imágenes de satélite TRMM. Otto et al. (2011) concluyeron que en esta región existen HAA conectados a procesos hidrológicos como la escorrentía producida por el derretimiento de nieve en la época seca, mientras que otros dependen de las lluvias que ocurre en la época húmeda, sugiriendo que esta relación debería evaluarse en otras regiones donde ocurren los HAA.

En este estudio, el objetivo fue validar la metodología desarrollada por Otto et al. (2011) en una región de los Andes del norte del Perú, específicamente en la cabecera de cuenca del rio Santa, en la ecorregión Puna húmeda. Esta cuenca en general viene experimentado los impactos negativos del cambio climático como el acelerado retroceso de sus glaciares. Por otra parte, en los últimos años ha habido un creciente interés de las poblaciones locales y regionales por conservar sus HAA ante posibles cambios que se pueden dar en el uso del suelo. Por lo tanto, se requiere contar con información detallada sobre la distribución espacial y temporal de los HAA, de manera que dicha información sirva de línea base para realizar acciones orientadas a incluir a estos ecosistemas en le gestión del agua por cuenca, dado que son ecosistemas dependientes directamente del agua. De igual manera dicha información servirá para elaborar propuestas de delimitación de zonas de protección de nacientes de agua y de regulación hídrica en las cabeceras de cuenca alto andinas.

\section{Área de estudio.}

El área de estudio se ubica en la cuenca alta del río Santa, en la cordillera occidental de los Andes del norte del Perú entre las coordenadas $09^{\circ} 55^{\prime}$ 09' ' y $10^{\circ}$ $13^{\prime} 35^{\prime}$ de latitud sur y $77^{\circ} 21^{\prime} 21^{\prime}$ y $77^{\circ} 10^{\prime} 09^{\prime}$ ' de longitud oeste. Cubre un área de $292 \mathrm{~km}^{2}$ y tiene una altitud media de 4285 msnm. Políticamente el área de estudio forma parte de la provincia de Recuay con el distrito de Catac y Bolognesi con los distritos de Chiquian y Aquia. Ecológicamente se encuentra dentro de la ecorregión Puna (Brack \& Mendiola, 2000), más propio de una Puna húmeda (Olson et al., 2001). En ella se encuentra la laguna Conococha a $4050 \mathrm{msnm}$, de aproximadamente de $2 \mathrm{~km}^{2}$ y una profundidad de 4,5 m. La delimitación estuvo en función de criterios eco-hidrológicos, incluyéndose la cuenca colectora de la laguna Conococha, como otras de los HAA, los que forman el complejo de HAA más grande de la cuenca del río Santa (Figura 1).

\section{Materiales.}

Imágenes satelitales.

Para la delimitación de los HAA de la cuenca se utilizaron dos imágenes de satélite Landsat ETM de $30 \mathrm{~m}$ de resolución espacial, y corregidas por el fallo SLC-OFF. Las imágenes fueron del 20 de julio de 2011 época seca (Figura 2) y del 27 de mayo de 2012 al final de la húmeda. Las imágenes se obtuvieron del USGS (US Geological Survey, 2013). 


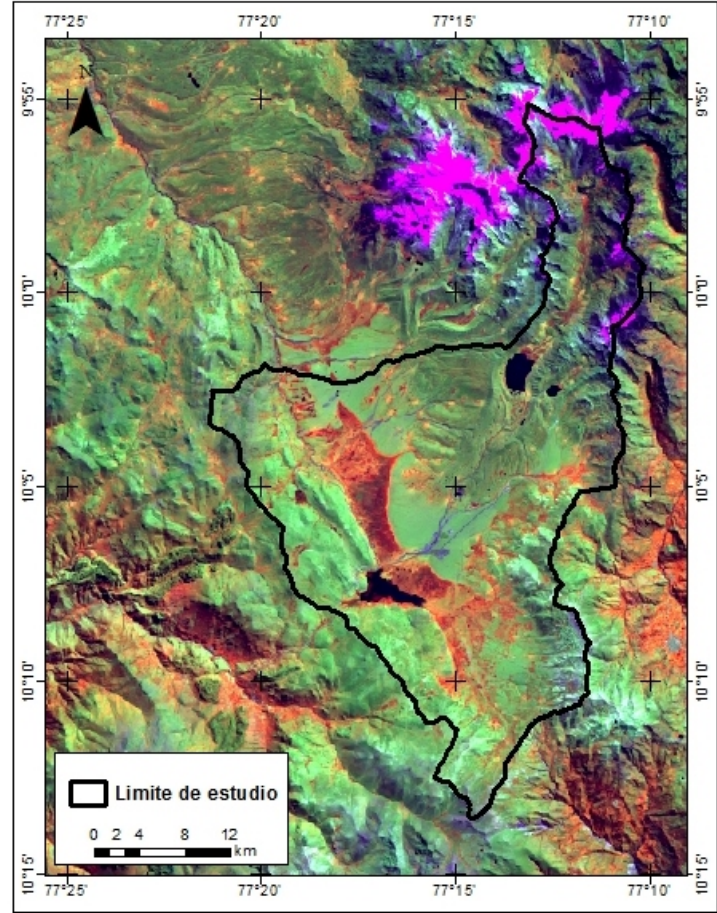

Figura 2. Imagen Landsat en la cuenca de estudio a finales de la época seca (falso color, bandas 453 RVA).

Para analizar la distribución temporal de los HAA y su dependencia con la precipitación pluvial y nival fueron usados los productos del satélite Moderate Resolution Imaging Spectroradiometer - MODIS: MOD13Q1, MOD10A2 y del satélite Tropical Rainfall Measuring Mission- TRMM: TMPA $3 B 43$. El primer producto MODIS es el Índice de la Diferencia Normalizada de la Vegetación (NDVI) proveído cada 16 días a una resolución de $250 \mathrm{~m}$ (Figura 3) y el segundo es un producto de nieve proveído cada 08 días a una resolución espacial de 500 m. El producto TRMM-TMP 3B43 expresa la tasa de precipitación de manera mensual a una resolución de $0.25^{\circ}(\sim 27 \mathrm{~km})$. Este producto se deriva de los datos TRMM-3B42 de cada tres horas con otros productos satélites y una grilla global de precipitación basada en estaciones de campo. Las imágenes usadas en esta parte del estudio se obtuvieron del Land Processes Distributed Active Archive Center- LP-DAAC, National Snow and Ice Data Center- NSIDC y Goddard Earth Sciences, Data and Information Services Center - GES DISC. El periodo de tiempo analizado fue entre los años 2000 - 2009.

Información meteorológica.

Para validar la información de lluvia del producto TRMM-TMPA 3B43 se usó la información de precipitación de cuatro estaciones meteorológicas del Servicio Nacional de Meteorología e Hidrología SENAMHI, cuya información fue disponible para el periodo analizado en la zona de estudio. Las estaciones fueron: Chiquián, Mayorarca, Recuay y Millpo.

Trabajos de campo.

Las informaciones de campo fueron recogidas en el mes de julio de 2013. Los equipos y materiales fueron: equipo GPS navegador marca Garmin, modelo 76CSx, de Exactitud +/- 10 m; binoculares Bushnell Insta-Focus $10 \times 50$, campo $5.5^{\circ}$; cámara fotográfica Canon; cinta métrica; imagen de satélite Landsat 8, impresa, del 26 de junio de 2013 y libreta de campo.

Se recorrió y recogió información sobre la vegetación de los HAA y las principales coberturas del suelo de la cuenca de estudio, que ya previamente se habían identificado, en gabinete, para su caracterización con el fin de identificar los tipos de vegetación predominantes y relacionarla con los patrones espectrales y espaciales que registran las imágenes de satélite Landsat.

\section{Metodología.}

La metodología consistió en identificar y delimitar espacialmente los HAA en base a las imágenes Landsat, definiendose primero los tipos y subtipos de HAA. Luego, la distribución espacial y temporal de los HAA usando las imágenes MODIS para el periodo 2000-2009. Con esta última información fue posible evaluar la dependencia de la extensión de los HAA

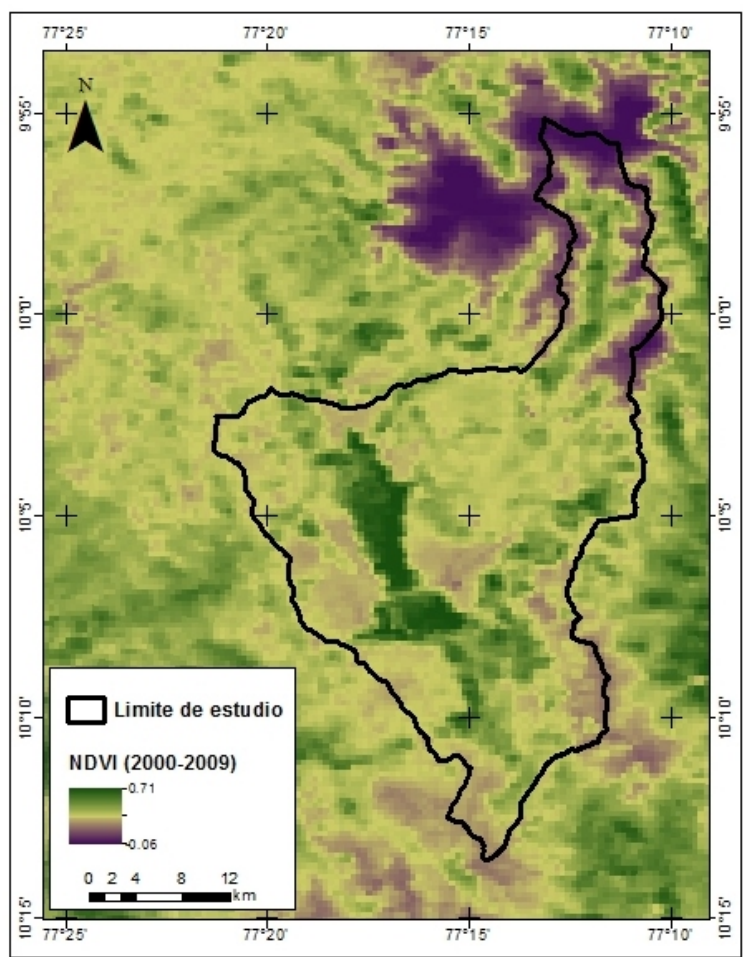

Figura 3. Promedio multianual (2000-2009) del índice de vegetación NDVI MODIS de finales de la época seca. En tonos verdes se muestra la vegetación intensa. 


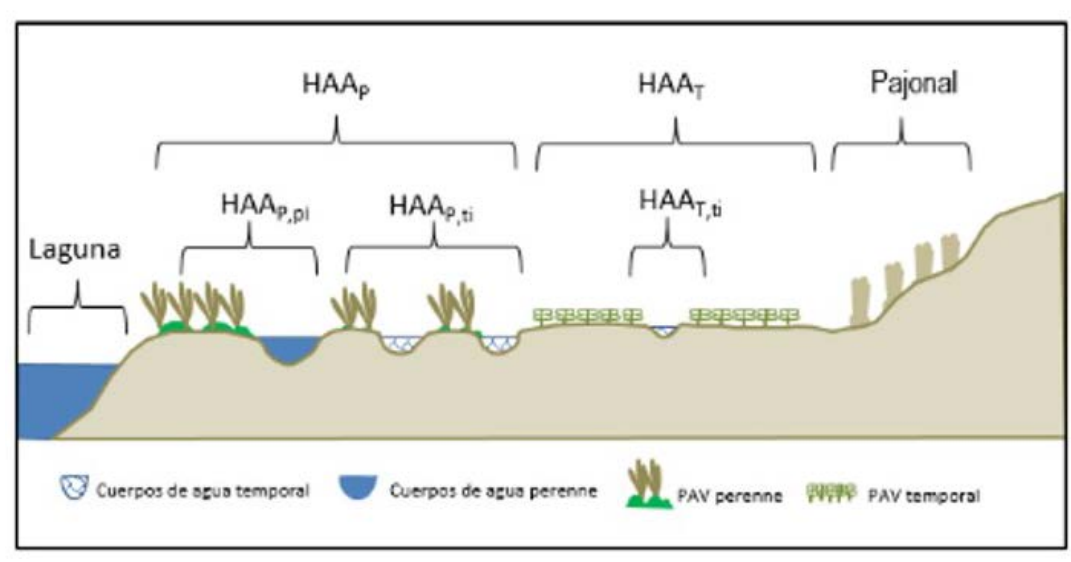

Figura 4. Esquema de clasificación de los tipos y subtipos de HAA en el área de estudio.

con las condiciones climáticas locales, específicamente de la precipitación pluvial y nival. Definición de tipos y subtipos de haa.

De acuerdo con Otto et al. (2011), primero se definieron dos tipos de HAA: perennes $\left(\mathrm{HAA}_{\mathrm{P}}\right.$ ) y temporales $\left(\mathrm{HAA}_{\mathrm{T}}\right)$. Esta diferenciación se basó en los cambios estacionales de la Vegetación Fotosintéticamente Activa (VFA), expresada por los cambios en el NDVI. A diferencia de los $\mathrm{HAA}_{\mathrm{T}}$, los HAA $_{P}$ contienen constantemente una alta fracción de VFA en un año hidrológico. Por otra parte, dentro de los $\mathrm{HAA}_{\mathrm{P}} \mathrm{y} \mathrm{HAA}_{\mathrm{T}}$ existen áreas anegadas o cubiertas de pequeños cuerpos de agua y riachuelos de manera temporal o perenne, indicadoras de la interacción y conexión con los flujos de agua superficial y subterránea. Esta diferenciación fue por el uso del Índice Infrarrojo de Diferencias Normalizadas (NDII), que expresa los cambios en el contenido de agua de la vegetación. A diferencia de Otto et al. (2011) que solo identificaron dos subtipos de HAA: HAAp temporalmente inundado (HAAP,ti), HAAT temporalmente inundado (HAAT,ti), en este estudios se identificó un nuevo subtipo denominado HAAp perennemente inundado (HAAP,pi) que no se presentó en la región sur. Este nuevo subtipo se refiere a la presencia perenne de agua, estancada o corriente, dentro de los HAA que fue posible notar en el NDII en ambas épocas de las imágenes usadas (seca y húmeda).

En el caso de los HAA “temporalmente inundados", se refiere a aquellas zonas que luego de la época de precipitación se inundan de agua de manera temporal.

El nuevo esquema de clasificación de los tipos y subtipos de HAA para la zona de estudio se ven en la Figura 4.

Delimitación de haa usando datos landsat.

El método consistió en aplicar una clasificación digital de forma gradual o escalonada, sobre las imágenes de satélite de la época seca (julio 2011) y húmeda (mayo 2012) a través del establecimiento de una serie de reglas de decisión o umbrales. Este tipo de método de clasificación se conoce como clasificador en árbol y tiene la ventaja de ser sencillo y a la vez muy eficiente (Chuvieco, 1996).

El procedimiento conceptual utilizado para delimitar los HAA de la cuenca de estudio se ve en la Figura 5 y considera tres pasos: Los dos primeros pasos se usan para delimitar los HAA separándolos de las otras coberturas y diferenciarlos en función de su

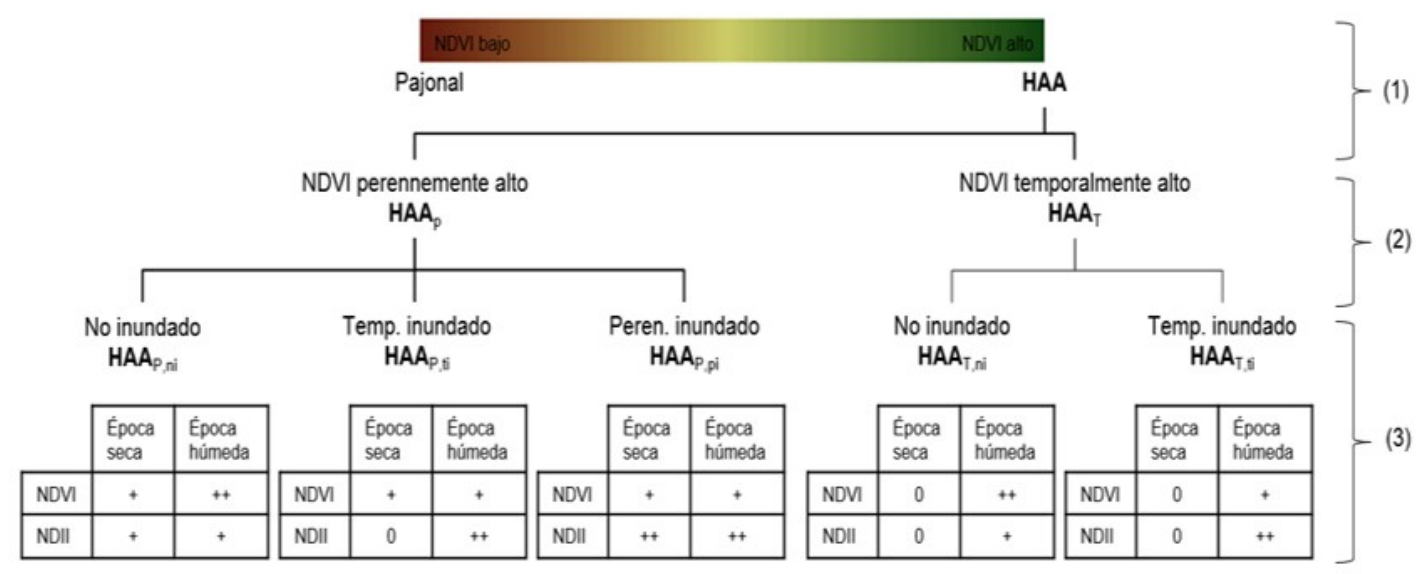

Figura 5. Esquema de clasificación de los tipos y subtipos de HAA en el área de estudio. (Adaptado de Otto et al., 2011). 
vigor vegetal estacional, $\mathrm{y}$ solo interviene el NDVI, mientras que el tercer paso es para diferenciar los HAA en función de su contenido humedad e interviene tanto el NDVI como el NDII.

$$
\begin{aligned}
& N D V I=\frac{\rho_{N I R}-\rho_{R E D}}{\rho_{N I R}+\rho_{R E D}} \\
& N D I I=\frac{\rho_{N I R}-\rho_{S W I R}}{\rho_{N I R}+\rho_{S W I R}}
\end{aligned}
$$

Tabla 1. Extensión de HAA obtenidos de las imágenes de satélite en

\begin{tabular}{|c|c|c|c|c|c|}
\hline \multirow[b]{2}{*}{$\begin{array}{c}\text { Tipos de } \\
\text { HAA }\end{array}$} & \multicolumn{2}{|c|}{ 2011-2012 } & \multirow{2}{*}{$\begin{array}{l}\text { Subtipos } \\
\text { de HAA }\end{array}$} & \multicolumn{2}{|c|}{ 2011-2012 } \\
\hline & $\begin{array}{c}\text { Superficie } \\
\text { (ha) }\end{array}$ & $\begin{array}{c}\text { Superficie } \\
(\%)\end{array}$ & & $\begin{array}{l}\text { Superficie } \\
\text { (ha) }\end{array}$ & $\begin{array}{c}\text { Superficie } \\
(\%)\end{array}$ \\
\hline \multirow{3}{*}{ HAАр } & \multirow{3}{*}{4881.24} & \multirow{3}{*}{66.1} & HAAP.pi & 94.5 & 1.9 \\
\hline & & & HAAP.ti & 499.86 & 10.2 \\
\hline & & & HAAp.ni & 4286.88 & 87.8 \\
\hline \multirow{2}{*}{$\mathrm{HAA}_{\mathrm{T}}$} & \multirow{2}{*}{2507.94} & \multirow{2}{*}{33.9} & HAA $_{\text {T.ti }}$ & 8.46 & 0.3 \\
\hline & & & HAAт.ni & 2499.48 & 99.7 \\
\hline Total & 7389.18 & 100 & & & \\
\hline
\end{tabular}
el presente estudio.
Dónde: infrarrojo cercano $\left(\rho_{\mathrm{NIR}}\right)$, infrarrojo de onda corta $\left(\rho_{\mathrm{SWIR}}\right)$ y rojo $\left(\rho_{\mathrm{RED}}\right)$.

Delimitación de haa usando datos modis.

A fin de incorporar la dinámica temporal de los HAA de la cuenca, se usó el producto de vegetación MODIS MOD13Q1. Este producto se usará para estimar la extensión de los HAA perennes y temporales para el periodo comprendido entre los años 2000-2009, para luego correlacionar la extensión de los HAA con los datos de lluvia TRMM-TMPA 3B43 y la extensión de la cobertura de nieve de las imágenes MODIS MOD10A2 para el mismo periodo de tiempo.

Previamente, se calculó un valor umbral para separar la cobertura de HAA y $_{\text {HAA }}$ en base a los NDVI calculados de dos imágenes MODIS MOD09GA, que coincidían con las fechas de las

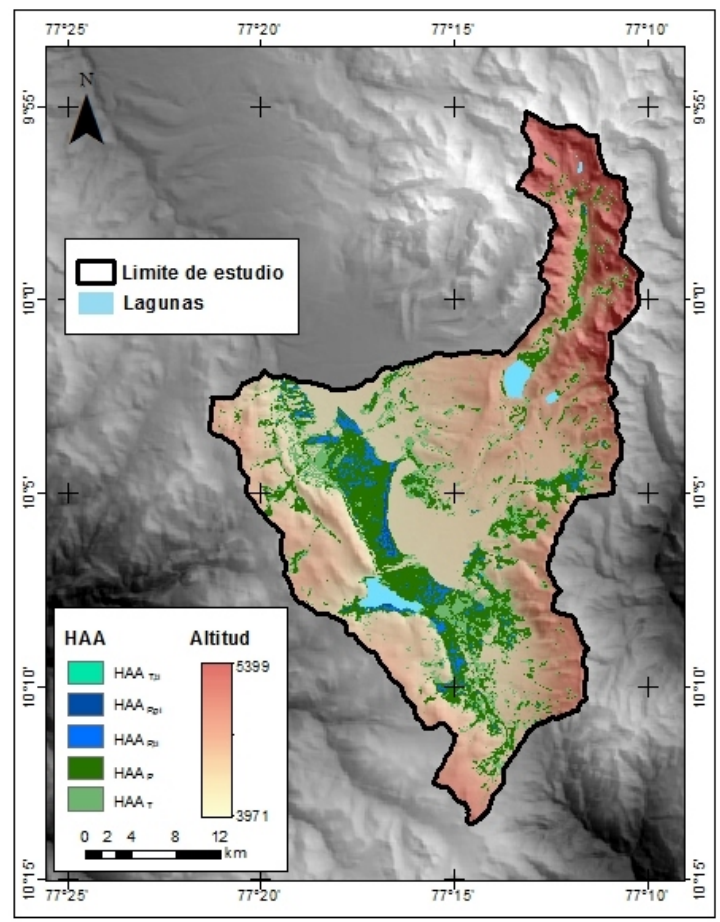

Figura 6. Mapa de los tipos y subtipos de HAA identificados en la cuenca de estudio. imágenes de satélite Landsat ETM procesadas (julio de 2011 y mayo de 2012).

El umbral mencionado se calculó para la época seca y húmeda, y fue dejado invariable, aplicándose al periodo de análisis (2000-2009). Esto permitió analizar los cambios ocurridos en la extensión espacial de los HAA, tomando como referencia el mismo nivel de la VFA alcanzado en los años 2011 y 2012. La idea central fue evaluar si la cobertura de HAA tuvo siempre la misma extensión espacial en otros años.

Análisis de la conexión de los haa y la precipitación pluvial y nival.

En este análisis se usó la extensión de HAAP y $\mathrm{HAA}_{\mathrm{T}}$ calculados de las imágenes MODIS, los datos TRMM previamente validados con la información de SENAMHI y los datos de cobertura de nieve MODIS.La hipótesis en esta parte del análisis fue evaluar si la extensión de los HAAp de la cuenca están correlacionados con la extensión de la cobertura de nieve acumulada durante los meses de junio, julio y agosto como sugieren Otto et al. (2011). En este estudio el mes de agosto no se usó, ya que la imagen de época seca corresponde al mes de julio. La hipótesis a validar es si la nieve acumulada durante los meses de la época seca contribuye al escurrimiento superficial en una época del año donde no hay precipitación directa y esto se refleja en la extensión de los HAA de la cuenca.

Igualmente, la otra hipótesis a validar es que existe una correlación entre la extensión de los $\mathrm{HAA}_{\mathrm{T}}$ y la precipitación acumulada durante los meses de marzo, abril y mayo. Aquí la hipótesis es que la precipitación acumulada durante la época húmeda influirá en la extensión de los $\mathrm{HAA}_{\mathrm{T}}$ de la cuenca afínales de dicha época.

Validación de la extensión de haa.

Para la validación de la extensión de los HAA delimitados en la cuenca de estudio, se utilizó la información recogida en campo de las principales cubiertas del suelo y se analizó en base a una matriz de error (Congalton, 1991). Por otra parte, a manera de comparación, se usó la información cartográfica sobre bofedales del Mapa de Cobertura Vegetal del Perú (MINAM, 2012). Dicha información estaba en formato shapefile de ESRI y también fue generada 

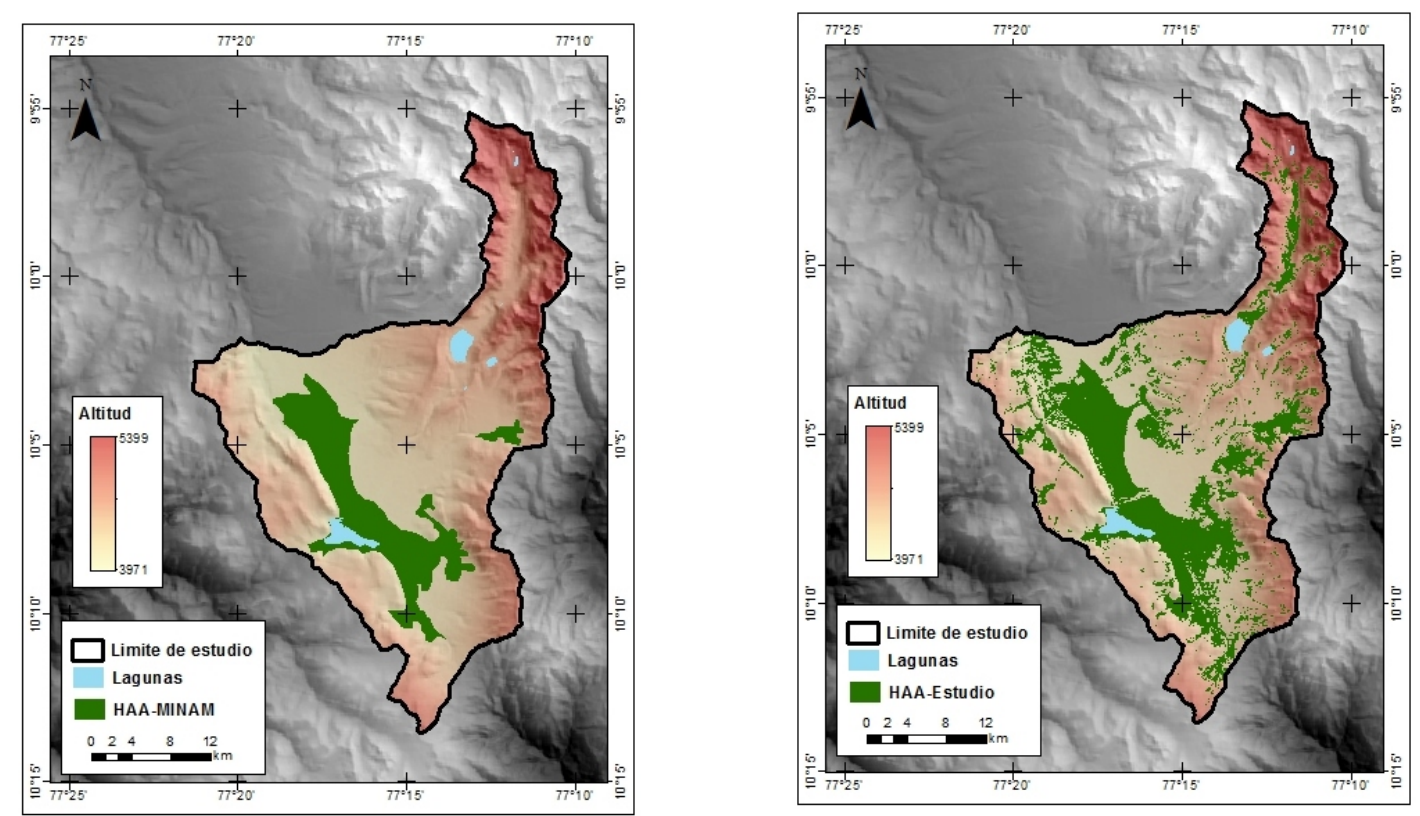

Figura 7. Comparación entre la información actual que existe sobre HAA en el Perú del MINAM (izquierda) y la información generada en este estudio (derecha).

usando imágenes de satélite Landsat, pero con métodos convencionales de interpretación visual y digitalización en pantalla (MINAM, 2012). También contó con control de campo y su escala de trabajo fue 1:100 000 con una Mínima Unida Cartografiable (MUC) de 25 ha (MINAM, 2012).

\section{Resultados y discusión.}

Se determinó que existe una gran extensión de HAA en la cabecera de cuenca del rio Santa. De las 29128.8 ha que abarca el área de estudio, la extensión de HAA se calculó en 7389.2 ha, que representa el $25 \%$ de la extensión de la cuenca. De este $25 \%$, el $66 \%$ se clasificaron como HAA perennes (HAAP) y el $34 \%$ como HAA temporales $\left(\mathrm{HAA}_{\mathrm{T}}\right)$. En cuanto al grado de inundación, los $\mathrm{HAA}_{\mathrm{P}}$ se subdividieron en perennemente inundados (HAAp,pi) y temporalmente inundados $\left(\mathrm{HAA}_{\mathrm{P}}, \mathrm{ti}\right)$, que representan el $2 \%$ y el $10 \%$ respectivamente, y los $\mathrm{HAA}_{\mathrm{T}}$ se subdividieron en temporalmente inundados $\left(\mathrm{HAA}_{\mathrm{T}}, \mathrm{ti}\right)$ que representa apenas el $0.3 \%$ (Figura 6 y Tabla 1 ).

Con respecto a la validación de la extensión de los HAA cartografiados en el año 2011-2012, se elaboró una matriz de error, con la información recogida en campo. Como resultado se obtuvo que la fiabilidad global de la información generada sobre la extensión de los HAA, con la metodología empleada fue de 99\%. Entonces, esto demuestra el gran potencial de la metodología seguida para identificar y delimitar HAA. Por ellos, en este estudio fue posible determinar humedales de hasta un pixel de extensión (30 x 30 m para las imágenes Landsat), aunque de acuerdo a Ozesmi \& Bauer (2002) y Thompson et al. (2002), se recomienda una MUC de 9 a 25 pixeles, en función de las características del paisaje. En el caso de los HAA una extensión mínima de 0.8 ha fue utilizada por García \& Lleellish (2012) para identificar los bofedales de la cuenca alta del rio Acarí en Arequipa, Perú, usando imágenes de satélite Landsat.

Se comparó los resultados de la metodología aplicada con la información actual que existe sobre los HAA en el Perú (MINAM, 2012) para la cuenca de estudio, Figura 7. Cabe señalar que aunque ambas fuentes se encuentran a la escala 1:100 000, a simple vista es evidente el nivel de generalización de la información actual sobre bofedales (MINAM, 2012) no obstante de que ha sido elaborada con el mismo tipo de imágenes de satélite Landsat utilizadas en este estudio, pero con fines y metodologías distintas. En el caso de la información del MINAM (2012) solo considera aquellos HAA mayores de 25 ha ya que es un trabajo de alcance nacional. A manera de análisis, si hacemos un cálculo de la extensión de HAA que se dejarían fuera en el área de estudio al considerar una MUC de 25 ha, esta asciende a 38\%, la cual viene a ser una extensión bastante significativa que no puede dejarse fuera cuando se trabaja a nivel de cuenca usando este tipo de imágenes.

En relación a los cambios en la extensión espacial y temporal de los HAA, (Figura 8), se observa la frecuencia de ocurrencia de los HAAp en la cuenca de estudio. Los números dentro de los recuadros en dicha figura, indican el número de años en que el área fue cartografiada como HAA. En color verde oscuro se muestran, por ejemplo, aquellas áreas que fueron 


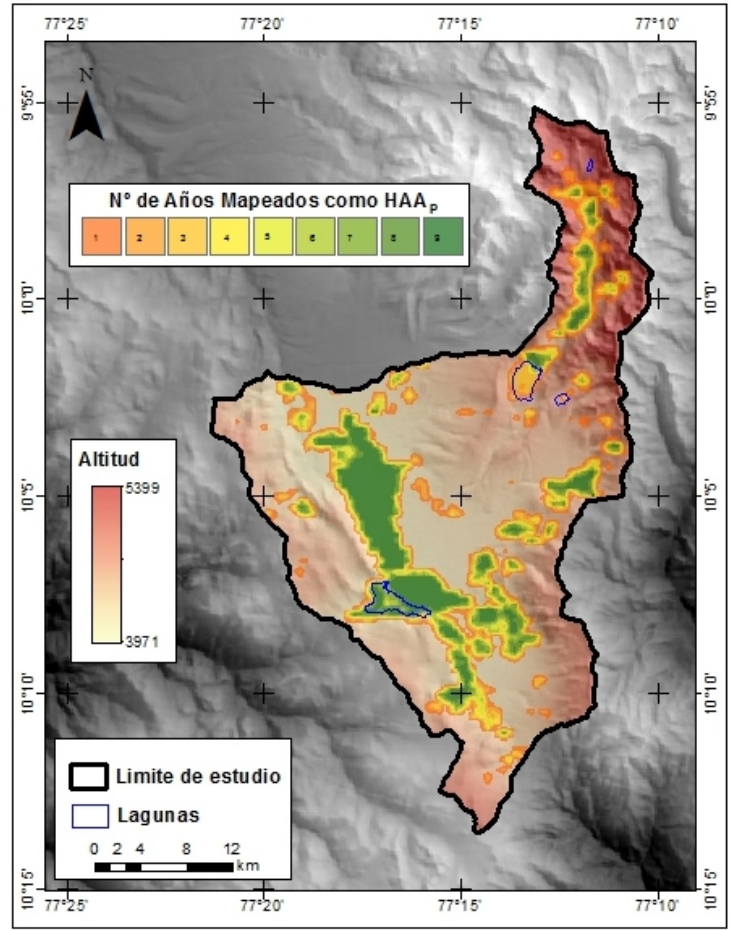

Figura 8. Cambios en la distribución espacial de los HAAP en los nueve años analizados en la cuenca de estudio.

constantemente cartografiadas como HAAp los nueve años de análisis y que equivalen al $6 \%$ de la cuenca.

A pesar de la diferencia en la resolución espacial de las imágenes Landsat y MODIS, se pudo notar que no toda la extensión de HAAp cartografiados durante el año 2011-2012 fueron siempre cartografiados en otros años, principalmente debido a forzadores climáticos o antrópicos. Por otro lado, en el caso de la extensión de $\mathrm{HAA}_{\mathrm{T}}$, fue altamente variable con cerca

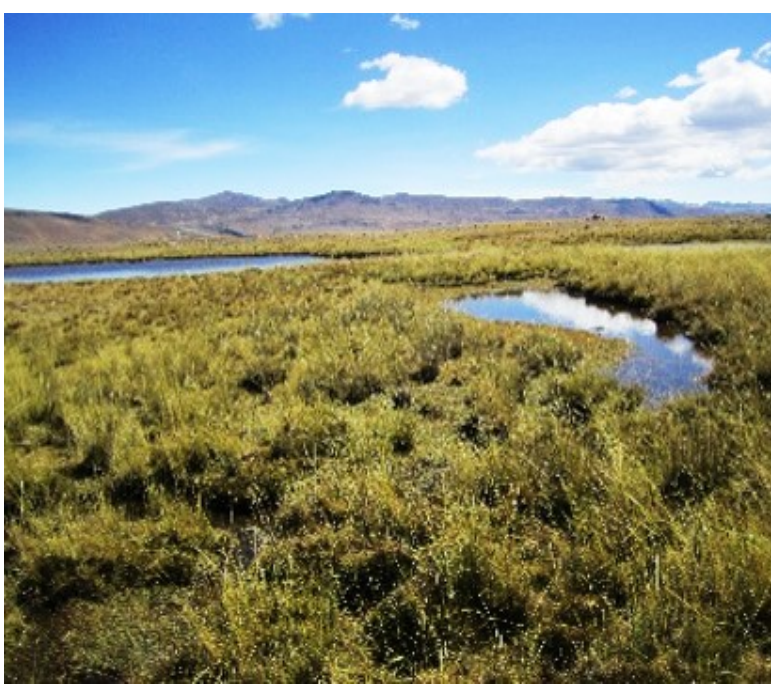

0.1\% cartografiados en los nueve años de análisis y $13 \%$ cartografiados en un solo año.

En la Figura 8, también se muestra la capa de los cuerpos de agua de la cuenca. Se puede ver que en la laguna Aguascocha durante la época seca y antes de que fuera represada en el año 2003, existía una importante extensión de HAAp, identificada por las imágenes MODIS entre los años 2000-2003. Por otra parte, se observa que dentro de la laguna Conococoha existe una alta extensión de HAAp, la cual está más bien asociada al alto NDVI de la vegetación acuática. Esto es más notorio durante la época seca debido principalmente a la poca profundidad de la laguna y al mínimo nivel que alcanza el espejo de agua, lo cual puede ser un indicador de su grado de eutrofización. Sin embargo, cabe indicar que esta extensión se ve influenciada por otros factores como el tamaño de pixel de la imagen, cambios meteorológicos, así como la regla de operación por ejemplo en el caso de la laguna Aguascocha, represada en el año 2003.

De acuerdo a los trabajos de campo (Figura 9), los HAA $_{P}$ presentan un tipo de vegetación graminoide dominante, presente en mayor proporción que la vegetación pulvinada o acojinada. Presenta una alta VFA anual y se encuentra sobre suelos saturados de agua, muchas veces con agua estancada o corriente a través de canales naturales o artificiales, lo que favorece el desarrollo de estas comunidades vegetales que requieren la presencia perenne de humedad. Debido al difícil acceso para el ganado, se pudo notar que estos humedales están menos impactados por el pastoreo.

En el caso de los $\mathrm{HAA}_{\mathrm{T}}$, su extensión fue altamente variable durante los años analizados. Predomina la vegetación cespitosa a ras del suelo, su VFA varía en función de la mayor o menor disponibilidad de agua en el suelo, lo que está

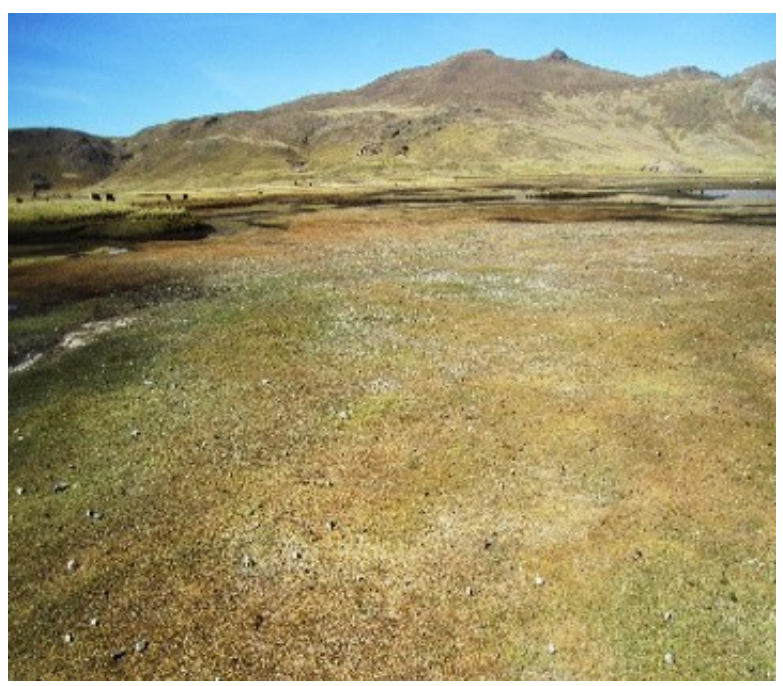

Figura 9. HAA perenne (izquierda) y HAA temporal (derecha) en la cabecera de cuenca del rio Santa. 


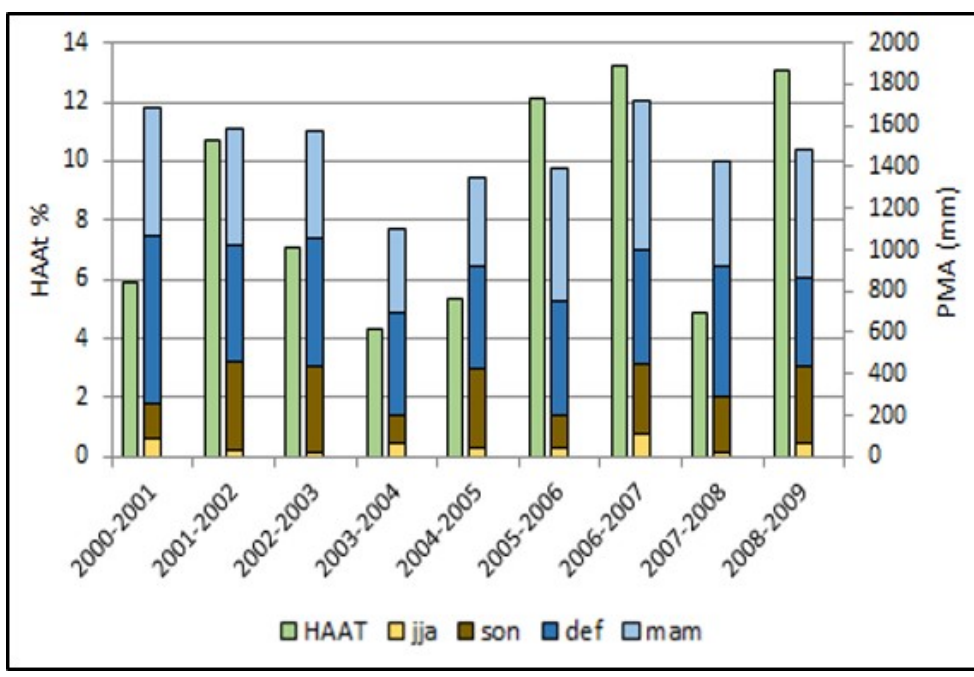

$\mathrm{HAA}_{\mathrm{T}}=$ humedales alto andinos temporales; $\mathrm{jja}=$ junio, julio y agosto; son= setiembre, octubre y noviembre; def= diciembre, enero y febrero; mam= marzo, abril y mayo; PMA= precipitación media anual.

Figura 10. Gráfico de barra de la extensión de los $\mathrm{HAA}_{\mathrm{T}}$ (NDVI MODIS) y la lluvia estacional (TRMM).

estrechamente relacionado con la lluvia en la cuenca. Dado que el suelo está menos saturado o inundado, este tipo de HAA tiene una alta carga de ganado y está más impactado que los HAAp.

Los resultados del análisis de la lluvia TRMM para el periodo 2000-2009 y la extensión de los $\mathrm{HAA}_{\mathrm{T}}$ se muestran en la Figura 10. La lluvia se agrupó cada tres meses y se observa que su comportamiento es altamente variable con un máximo de $1700 \mathrm{~mm}$ en el año 2006-2007 y un mínimo de $1100 \mathrm{~mm}$ en el año 2003-2004. Esta situación es distinta a lo que sucede en la parte sur del Perú, donde la precipitación es mucho menor de 200 a $400 \mathrm{~mm}$, (Otto et al., 2011) por estar ubicada en la transición entre la Puna húmeda y seca. La distribución estacional de la precipitación muestra que entre los meses de diciembre a mayo, se produce en promedio el $76 \%$ de la precipitación, mientras que entre los meses de junio a agosto apenas el $4 \%$. También se observa que los años con mayor y menor precipitación coinciden con los años de mayor y menor extensión de $\mathrm{HAA}_{\mathrm{T}}$, esta relación se demuestra estadísticamente más adelante.

La Figura 11 muestra la extensión de la nieve acumulada entre los años 20002009, para los meses de junio y julio. En esta parte del análisis se tuvo que seleccionar una extensión mayor que la cuenca original, con el objetivo de tener una mayor representatividad de la nieve caída en la región. Asimismo, esta nueva área permitió incorporar nuevas extensiones de $\mathrm{HAA}_{\mathrm{P}}$ para efectos de mejorar la robustez del análisis. En el caso de la cuenca de estudio, se optó por solo incluir a los HAAp ubicados aguas arriba de la laguna Aguascocha, por considerarlos en su régimen hídrico natural para el periodo analizado.

En general se observa que la cobertura de nieve es alta y constate durante la mayoría de años (39\%), a excepción del año 2005-2006 en que sufrió una ligera disminución (33 \%). Esta situación es distinta a lo que sucede en la parte sur del Perú, donde la acumulación de nieve es menor y más variable (Otto et al., 2011). Por otra parte se puede apreciar en la Figura 10 que generalmente los años con mayor y menor acumulación de nieve coinciden con los años de mayor y menor extensión de HAAp. En base a estos resultados podemos afirmar que durante los años de menor caída de nieve la extensión de los $\mathrm{HAA}_{\mathrm{p}}$ disminuye, pero esta diminución está más relacionada a una pérdida del vigor de la vegetación de los HAA (reducción de la VFA) debido a una menor disponibilidad de agua que a una desaparición en el terreno o un cambio en el uso del suelo. Esta relación deberá comprobarse con datos medidos en campo.

Con el fin de evaluar las dos relaciones encontradas, se procedió a realizar dos análisis de correlación que se muestra en las Figuras 12 y 13. En

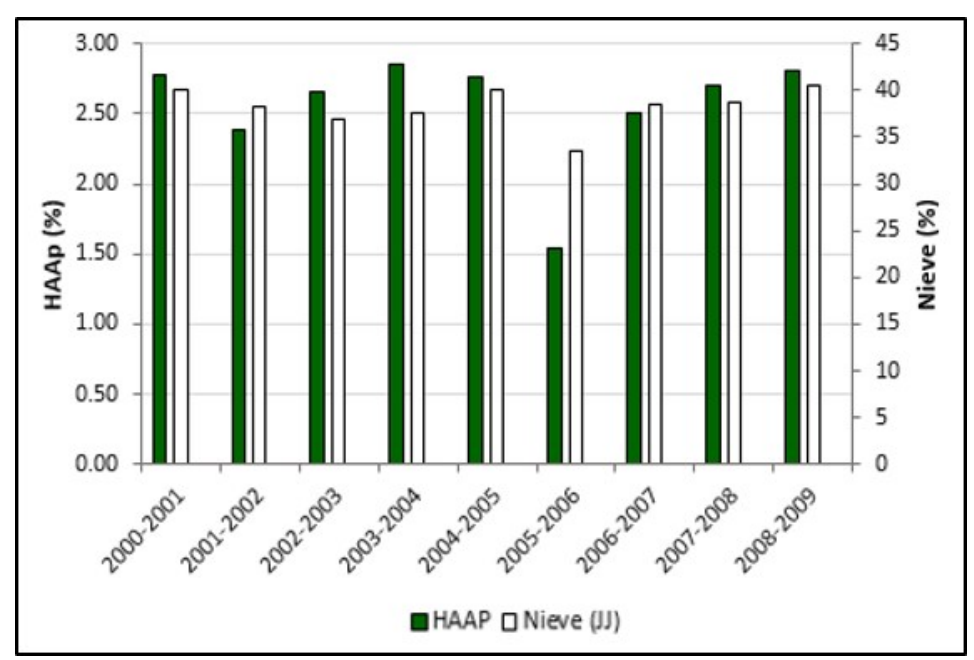

HAAp $=$ Humedales Alto Andinos Perennes; $j \mathrm{j}=$ junio y julio.

Figura 11. Gráfico de barra de la extensión de los HAAP (NDVI MODIS) y la nieve estacional caída en junio y julio (MOD10A2 MODIS). 


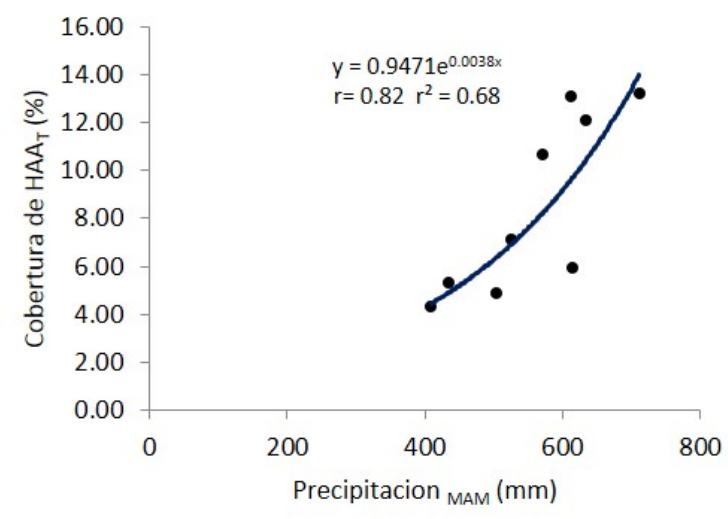

$\mathrm{HAA}_{\mathrm{T}}=$ Humedales Alto Andinos Temporales; mam= marzo, abril y mayo.

Figura 12. Correlación entre la extensión de HAA $_{\text {T }}$ (MODIS) y la precipitación (TRMM).

estos análisis se determinó estadísticamente que existe una dependencia ente la extensión de los HAAP y la acumulación de nieve durante la época seca (meses de junio y julio), indicado por el coeficiente de determinación $\left(r^{2}=0.71\right)$. En el caso de la extensión de los $\mathrm{HAA}_{\mathrm{T}}$, se determinó estadísticamente que existe una dependencia entre la extensión de los $\mathrm{HAA}_{\mathrm{T}}$ con la lluvia acumulada durante los meses de marzo a mayo, indicado por el coeficiente de determinación $\left(\mathrm{r}^{2}\right.$ $=0.68)$.

La existencia de $\mathrm{HAA}_{\mathrm{P}}$ cartografiados constantemente en la época seca es un indicador de su dependencia de distintas fuentes de agua como las provenientes de las quebradas y el deshielo de los glaciares, no solo de la precipitación. Por otra parte, la extensión de $\mathrm{HAA}_{\mathrm{T}}$ cartografiados como temporales en la época húmeda es un indicador de su dependencia de los patrones espaciotemporales de lluvia en la cuenca.

\section{Conclusiones.}

En la cuenca alta del rio Santa existe una gran extensión HAA, que representa el $25 \%$ de la extensión de la cuenca de estudio. De este 25\% de HAA, el 66\% fueron clasificados como perennes y el 34\% como temporales.

Los resultados obtenidos, contra la información actual sobre HAA (MINAM, 2012) usando el mismo tipo de imágenes de satélite, se comprueba que se dejarían fuera al 38\% de la extensión de HAA, por lo tanto la metodología aplicada mostró mayor identificación de HAA y puede ser utilizada para generar información más detallada sobre HAA a nivel de cuenca.

Se demostró estadísticamente que existe una dependencia ente la extensión de los HAA perennes de la cuenca con la acumulación de nieve durante la

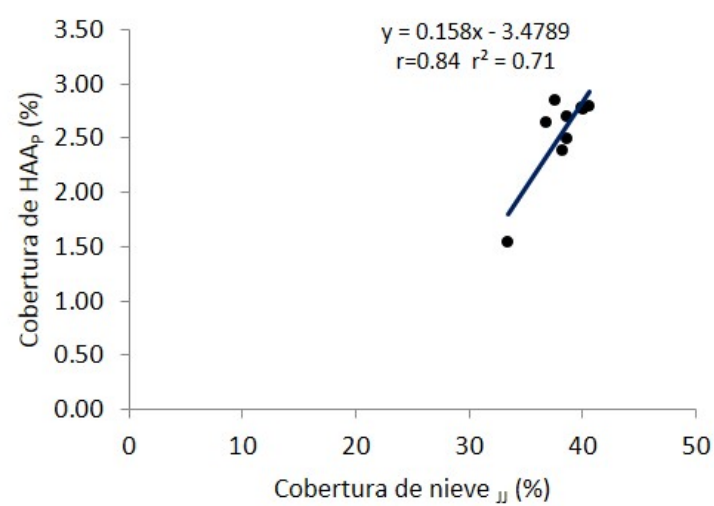

$\mathrm{HAA}_{\mathrm{P}}=$ Humedales Alto Andinos Temporales; $\mathrm{jj}=$ junio y julio.

Figura 13. Correlación entre la extensión de HAAP $_{P}$ (MODIS) y la acumulación de nieve

época seca y una dependencia entre la extensión de los HAA temporales con la lluvia acumulada durante época húmeda. Estos resultados confirman la misma dependencia encontradas en el trabajo de Otto et al. (2011) dentro de la ecorregión de puna seca, aunque esta primera relación deberá validarse con datos de caudales medios en campo. Esto demuestra que los humedales se encuentran vinculados de manera perenne o temporal a la presencia de agua, por lo tanto requieren de ésta en cantidad, calidad y temporalidad adecuadas para mantener su integridad ecológica y la provisión de sus servicios ecosistémicos.

En la cuenca alta del río Santa, los HAA son el principal medio de vida de la población la disminución en la extensión de los HAA afectará la provisión de estos servicios. Por otro lado, si los HAA de la cuenca se mantienen en buenas condiciones ecohidrológicas pueden contribuir a mitigar los efectos del cambio climático, ya que estos actúan como sumideros de carbono. Por ello, esta información puede contribuir a desarrollar estrategias de adaptación ante los efectos adversos del cambio climático.

Los resultados demuestran la utilidad de los datos obtenidos de satélites de observación terrestre como Landsat, MODIS y TRMM, para generar información sobre HAA, de manera que contribuya a su conservación y protección. Aunque con esta metodología es posible determinar HAA en base al tamaño del pixel, se recomienda usar como mínimo 9 pixeles como MUC, que equivaldría a 0.8 ha y 56 ha para Landsat y MODIS respectivamente.

\section{Agradecimientos.}

A M. A. Lleellish y J. Odar por su apoyo en la coordinación e identificación de especies vegetales de los HAA durante los trabajos de campo desarrollados 
en julio de 2013. De igual manera a R. Dickson en el procesamiento SIG.

\section{Literatura citada.}

Alzérreca H., Luna D., Prieto G., Cardozo A. \& Céspedes J. 2001. Estudio de la capacidad de carga de bofedales para la cría de alpacas en el sistema TDPS-Bolivia. Informe final de consultoría. Asociación Integral de Ganaderos en Camélidos de los Altos Andes, Programa de las Naciones Unidas para el Desarrollo, Autoridad Binacional del lago Titicaca. La Paz, Bolivia. 278 pp.

Brack A. \& Mendiola C. 2000. Ecología del Perú. PNUD. Ed. Bruño. Lima, Perú.

Buytaert W., Cuesta-Camacho F. \& Tobón C. 2011. Potential impacts of climate change on the environmental services of humid tropical alpine regions. Global Ecology and Biogeography 20: 19-33.

Congalton R. G. 1991. A review of assessing the accuracy of classifications of remotely sensed data. Remote Sensing of Environment, 37:35-46.

Convención de Ramsar \& Grupo de Contacto EHAA. 2008. Estrategia Regional para la Conservación y Uso Sostenible de Humedales Altoandinos. Gobiernos de Ecuador y Chile, CONDESAN y TNC-Chile.

Convención de Ramsar. 2010. Inventario de humedales: Marco de Ramsar para el inventario y la descripción de las características ecológicas de los humedales. Manuales Ramsar para el uso racional de los humedales, $4^{\mathrm{a}}$ edición, vol. 15. Secretaría de la Convención de Ramsar, Gland (Suiza).

Chuvieco E. 1996. Fundamentos de Teledetección Espacial. Ed. RIALP, S.A. Madrid. Tercera Edición.

Diaz H. F., Grosjean M. \& Graumlich L. 2003. Climate variability and change in high-elevation regions: past, present and future. Climatic Change 59:1-4.

García E. \& Lleellish M. A. 2012. Cartografiado de bofedales usando imágenes de satélite Landsat en una cuenca altoandina del Perú. Revista de Teledetección 38: 92-108.

Gibbons R. E. 2012. Bird ecology and conservation in Peru's high andean peatlands. Tesis doctoral, Universidad Estatal de Louisiana State University Mechanical College, EEUU.

Haylock M. R., Peterson T. C., Alves L. M., Ambrizzi T., Anunciação Y. M. T., Baez J., Barros V. R., Berlato M. A., Bidegain M., Coronel G., García V. J., Grimm A. M., Karoly D., Marengo J. A., Marino M. B., Moncunill D. F., Nechet D., Quintana J., Rebello E., Rusticucci M., Santos J. L., Trebejo I., Vincent l. A. 2006. Trends in total y extreme South American rainfall in 1960-2000 and links with sea surface temperature. Journal of Climate, 19: 1490-1512.

Ministerio del Ambiente. 2012. Memoria Descriptiva. Mapa de cobertura vegetal del Perú. Lima: MINAM.

Moreau S., Bosseno R., Gu X. F. \& Baret F. 2003. Assessing the biomass dynamics of Andean bofedal and totora high-protein wetland grasses from NOAA/AVHRR. Remote Sensing of Environment. 85(4): 516-529.

Olson D. M., Dinerstein E., Wikramanayake E. D., Burgess N. D., Powell G. V. N., Underwood E. C., D'Amico J. A., Itoua I., Strand H. E., Morrison J. C., Loucks C. J., Allnutt T. F., Ricketts T. H., Kura Y., Lamoreux J. F., Wettengel W. W., Hedao P., Kassem K. R. 2001.Terrestrial ecoregions of the world: A new map of life on Earth. BioScience 51: 933-938.

Otto M., Scherer D. \& Richters J. 2011. Hydrology differentiation and spatial distribution of high altitude wetlands in a semi-arid Andean region derived from satellite data. Hydrology and Earth System Sciences. 15: 1713-1727.

Ozesmi S. L. \& Bauer M. E. 2002. Satellite remote sensing of wetlands. Wetland Ecology and Management, 10(5): 381-402.

Postigo J. C., Young K. R. \& Crews K. A.. 2008. Change and continuity in a pastoralist community in the high Peruvian Andes. Human Ecology. 36(4):535-551.

Quiroz R. \& Saatchi S. 1999. Mapping Aquatic and Agricultural Vegetation of Altiplano, Agriculture and Agroforestry Management. CIFOR, Lima, Peru.

Squeo F. A., Warner B. G., Aravena R. \& Espinoza D. 2006. Bofedales: High altitude peatlands of the central Andes. Revista Chilena de Historia Natural. 79: 245-255.

Tapia M. E. \& Flores J. A. 1984. Pastoreo y Pastizales de los Andes del Sur del Perú. INIPA. Lima-Perú.

Thompson M., Marneweck G., Bell S., Kotze D., Muller J., Cox D., \& Clark R. 2002. A methodology for a South African National Wetland Inventory. Department of Environmental Affairs and Tourism Report.

Treacy J. M. 1994. Las chacras de Coporaque, andenería y riego en el Valle del Colca. Instituto de Estudios Peruanos. Lima, 298 pp.

Washington-Allen R. A., Ramsey R., West N. E. \& Norton B. E. 2008. Quantification of the ecological resilience of drylands using digital remote sensing. Ecology and Society. 13, 33.

Zorogastúa-Cruz P., Quiroz R. \& Garatuza-Payan J. 2012. Dinámica de los bofedales en el altiplano peruanoboliviano. Revista Latinoamericana de Recursos Naturales. 8 (2):63-75.

\footnotetext{
${ }^{1}$ Dirección de Conservación y Planeamiento de Recursos Hídricos, Autoridad Nacional del Agua, Calle Diecisiete No 355, Urb. El Palomar, San Isidro, Lima, Perú. egarciag@ana.gob.pe

2 Department of Ecology, Technische Universität Berlin, Rothenburgstraße 12, 12165 Berlin, Germany.
} 